\title{
TINGKAT PARTISIPASI WANITA DALAM PEMBANGUNAN NON FISIK DI KEURAHAN KADIDI KECAMATAN PANCA RIJANG KABUPATEN SIDENRENG RAPPANG
}

\author{
1)Wahyuni, 2)Andi Astinah Adnan, ${ }^{3)}$ Kamaruddin Sellang \\ Fakultas IImu Sosial dan IImu PolitikUniversitas Muhammadiyah Sidenreng Rappang \\ wahyuni43162097.1b@gmail.com \\ andi.astinah.adnan@gmail.com \\ kamaruddinsellang@yahoo.co.id
}

\begin{abstract}
Abstrak
Penelitian ini bertujuan untuk mengetahui partisipasi wanita dalam pembangunan non fisik di Kelurahan Kadidi Kecamatan Panca Rijang Kabupaten Sidenreng Rappang dan untuk mengetahui faktor-faktor yang memengaruhi partisipasi wanita di Kelurahan Kadidi Kecamatan Panca Rijang Kabupaten Sidenreng Rappang.Populasi penelitian ini adalah sebanyak 411 wanita.Sampel sebanyak 80 orang.Teknik penarikan sampel yang digunakan yaitu Sampling Insidental.Tipe penelitian ini adalah deskriptif kuantitatif.Teknik pengumpulan data yang digunakan adalah observasi, kuesioner dan studi pustaka.Teknik analisis data yang digunakan adalah statistik deskriptif dan dengan bantuan aplikasi SPSS versi 21. Hasil penelitian menunjukkan bahwa Partisipasi Wanita di Kelurahan Kadidi dengan persentase $56.87 \%$ berada pada kategori kurang baik.Pembangunan Non Fisik di Kelurahan Kadidi dengan persentase $60 \%$ berada pada kategori kurang baik. Berdasarkan nilai $\mathrm{t}$ hitung $>\mathrm{t}$ tabel atau 6.415 $>0,219$ Jika nilai $\mathrm{t}$ hitung $\geq \mathrm{t}$ tabel, maka $\mathrm{HO}$ ditolak dan Ha diterima, artinya Signifikan, Jika nilai $t$ hitung $\leq \mathrm{t}$ tabel, maka $\mathrm{HO}$ diterima dan Ha ditolak, artinya tidak Signifikan, maka Ha diterima dan $\mathrm{HO}$ ditolak artinya Tingkat Partisipasi Wanita berpengaruh signifikan terhadap Pembangunan Non Fisik di Kelurahan Kadidi Kecamatan Panca Rijang Kabupaten Sidenreng Rappang dengan persentase sumbangan pengaruh 54,5\% berada pada tingkatan Sedang atau kategori kurag baik. Faktor-faktor yang Mempengaruhi Partisipasi Wanita: a. Faktor Internal: 1) Keiikutsertaan $59,2 \%$, 2) Pendidikan 62,2\%, 3) Penghaslan dan pendapatan 64,6\%. b. Faktor Eksternal: 1) Kepemimpinan 65,2\%, 2) Peralatan/ Fasilitas Pemerintah 60,6\%. Berdasarkan dari uraian tersebut di atas, maka dapat disimpulkan bahwa faktor-faktor yang mempengaruhi partisipasi wanita di Keurahan Kadidi berada pada kategori baik $62,36 \%$.

Kata kunci : Partisipasi Wanita dan Pembangunan Non Fisik
\end{abstract}

\section{Abstract}

This study aims to determine the participation of women in non-physical development in Kadidi Subdistrict, Panca Rijang Subdistrict, Sidenreng Rappang Regency and to determine the factors that influence women's participation in Kadidi Subdistrict, Panca Rijang Subdistrict, Sidenreng Rappang District.The population of this study was 411 women. A sample of 80 people. The sampling technique used is incidental sampling. This type of research is quantitative descriptive. Data collection techniques used were observation, questionnaire and literature study. The data analysis technique used is descriptive statistics and with the help of SPSS application version 21. The results showed that the Participation of Women in Kadidi Village with a percentage of 56.87\% was in the unfavorable category. Non-Physical Development in Kadidi Urban Village with a percentage of $60 \%$ is in the unfavorable category. Based on the value of $t$ arithmetic $>t$ table or $6,415>0,219$ If the value of $t$ arithmetic $\geq t$ table, then $\mathrm{HO}$ is rejected and $\mathrm{Ha}$ is accepted, meaning Significant, If the value of $t$ arithmetic $\leq t$ table, then $\mathrm{HO}$ is accepted and $\mathrm{Ha}$ is rejected, meaning that is not Significant, then Ha accepted and $\mathrm{HO}$ is rejected, it means that the Participation Rate of Women has a significant effect on Non-Physical Development in Kadidi Subdistrict, Panca Rijang Subdistrict, Sidenreng Rappang Regency with a contribution percentage of $54.5 \%$ being in the medium level or good kurag category. Factors Affecting Women's Participation: a. Internal Factors: 1) $59.2 \%$ participation, 2) Education $62.2 \%$, 3) Income and income $64.6 \%$. b. External Factors: 1) Leadership 65.2\%, 2) Government Equipment / Facilities 60.6\%. Based on the description above, it can be concluded that the factors that influence women's participation in the Kadidi Village are in the good category $62.36 \%$.

Keywords: Women's Participation and Non-Physical Development

PRAJA | Volume 9 | Nomor 1 | Edisi Februari 2021 


\section{A. PENDAHULUAN}

Undang-undang Nomor 25 Tahun 20114 tentang Sistem Perencanaan Pembangunan Nasional dan diatur oleh Menteri Perencanaan Pembangunan Nasional/Bappedas untuk tingkat Nasional dan Badan Perencaaa Pembangunan Daerah (Bappeda). Undang-Undang Nomor 6 Tahun 2014 Pasal 13 Ayat 10 yang berbunyi "Pembangunan Desa tujuannya meningkatkan kesejahteraan masyarakat Desa dana kualitas hidup manusia serta penanggulangan kemiskinan melalui persediaan pemenuhan kebutuhan dasar, pembangunan sarana dan prasarana, pengembangan potensi ekonomi lokal, serta pemanfaatan sumber daya alam dan lingkungan secaraberkelanjutan.

Berkaitan dengan proses pembangunan desa, maka partisipasi menjadi hal yang penting dilakukan karena partisipasi masyarakat sebagai bentuk keterlibatan anggota masyarakat dalam seluruh pembangunan yang meliputi kegiatan dalam perencanaan dan pelaksanaan program pembangunan. Partisipasi masyarakat dalam pembangunan adalah keterlibatan anggota masyarakat diwjudkan dalam aspek perencanaan dan pelaksanaan program pembangunan desa" (Agustin, 2014). Keadaan dan peran dan status wanita lebih dipengaruhi oleh masa lampau dan praktek hidup sehari-hari.Kurangnya perwakilan wanita dalam lembaga politik inilah yang kemudian mendorong dan melatar belakangi lahirya tuntutan agar wanita lebih diberi ruang dalam berpartisipasi.

Peran yang dilakukan wanita dalam kesertaannya di bidang pembangunan merupakan tindakan dalam rangka meningkatkan harkat serta kualitas dari wanita itu sendiri. Keterlibatan menjadi syarat dalam upaya mewujudkan pembangunan yang berkeadilan. Negara tidak akan mungkin sejahtera jika para wanita dibiarkan tertinggal, tersisih dan dan tertindas".(Manembu, 2005). Partisipasi memang telah lama menjadi penghias pemerintahan dari tingkat pusat sampai tingkat daerah.Partisipasi merupakan bentuk kegiatan dilaksanakan secara bersama dan dari partisipasi itulah yang menjadikan pekerjaan lebih mudah dan cepat terlaksana. Kulture yang memberikan pandangan tentang fungsi dari bagian tubuh pria dan e-ISSN 2716-165X

wanita akan berkosekuensi pada psikologisnya, dimana wanita lebih memiliki tugas domestic untuk mengurusi segala urusan rumah tangga, sedangakan pria dipersiapkan mandiri dengan peran yang lebih besar pada berbagai aspek.

Partisipasi wanita dalam pembangunan kelurahan khusunya pembangunan non fisik (sumber daya manusia) memenuhi 4 indikator yaitu, ekonomi, pendidikan, pembangunan manusia dan kesehatan yang meliputi pelatihan menjahit dan pelatihan pembuatan kue sebagai program untuk meningkatkan ilmu pengetahuan serta perekonomian wanita serta bidang kesehatan berupa pemeriksaan kesehatan secara rutin. Kedua ,Kehadiran wanita dalam program tersebut hanya diikuti oleh 31 dari 411 wanita yang ada di Kelurahan Kadidi serta pelatihan hanya dilakukan sekali pertemuan saja sehingga mengurangi minat wanita mengikuti program pembangunan non fisik di Kelurahan.

Fenomena yang terjadi diatas, maka calon peneliti memutuskan melakukan penelitian dengan judul Tingkat Patisipasi Wanita dalam Pembangunan Non Fisik di Kelurahan Kadidi Kecamatan Panca Rijang Kabupaten Sidenreng Rappang dengan tujuan untuk mengetahui Tingkat Partisipasi Wanita dalam Pembangunan Non Fisik di Kelurahan Kadidi Kecamatan Panca Rijang Kabupaten Sidenrang Rappang dan untuk mengetahui faktor-faktor yang mempengaruhi Tingkat Partisipasi Wanita dalam Pembangunan Non Fisik di Kelurahan Kadidi Kecamatan Panca Rijang Kabupaten Sidenreng Rappang.

\section{Partisipasi Wanita}

Ouchi dalam Remiswal (2013:29), terdapat perbedaan dimensi dan fase dalam partisipasi, misalnya partisipasi dalam identifikasi masalah, partisipasi dalam pengumpulan informasi dan diskusi kelompok tentang kebaikan dan kekurangan bergabung dalam suatu kegiatan, partisipasi dalam peran perencaan atau formulasi kegiatan, partisipasi dalam mobilisasi sumberdaya, partisipasi dalam implementasi, partisipasi dalam pembagian keuntungan, atau partisipasi dalam pemantauan dan evaluasi kegiatan. Peneliti menyimpulkan bahwa partisipasi merupakan kesediaan atau kesiapan seseorang baik jiwa maupun raganya dalam suatu hal, yang dinilai bermanfaat untuk dirinya sendiri maupun 
kelompoknya. Partisipasi wanita digunakan teori dari Yadav dalam Yuni Kurniyanti (2019: 45) "menegemukakan tentang lima macam partisipasi :

a) Partsipasi dalam Pengambialn Keputusan adalah partisipasi langsung dalam proses pengambilan keputusan tentang programprogram pembangunan di wilayah setempat atau ditingkat lokal.

b) Partisipasi daam Pelaksanaan Kegiatan adalah partisipasi yang berupa pemerataan sumbangan masyarakat dalam bentuk tenaga kerja, uang tunai atau beragam bertuk korbanan lainnya yang sepadan dengan pemanfaatan.

c) Partisipasi dalam Pemantauan dan Evaluasi Pembangunan yaitu partisipasi untuk mengumpulkan sebuah informasi yang memiliki kaitan terhadap perkembangan dalam kegiatan beseta perilaku aparat pembangunan.

d) Partisipasi dalam Pemanfaatan Hasil Pembangunan yaitu hal yang tidak bisa dikatakan berhasil jika tidak ada dukungan dari setiap partisipasi masyarakat.

\section{Konsep Pembangunan}

Menurut Saul M. Katz dalam Welasari \& Ardiensyah (2016:262) "mendefinisikan pembangunan sebagai perubahan yang berlangsung secara luas dalam masyarakat dan bukan sekedar pada sektor ekonomi saja melainkan sektor lainnya seperti perubahan pendapatan perkapita atau perubahan pada grafik tenaga kerja dan lainnya. Adapun pembangunan di Indonesia dapat dilakukan dalam dua aspek, yaitu :

a) Pembangunan Fisik, "Pembangunan secara fisik meliputi pembangunan jalan raya, pembangunan jembatan, pembangunan gedung, pembangunan pasar, dan lain sebagainya Pembangunan fisik dilakukan agar masyarakat dapat menggunakan sarana infrastruktur yang ada untuk menujang aktivitas kehidupan sehari - hari. Pembangunan fisik disini berarti proses pembangunan yang dilakukan yang berupa sarana yang dapat digunakan oleh masyarakat untuk memenuhi kehidupan sehari-hari".

b) Pembangunan Non Fisik "Pembangunan suatu wilayah tidak hanya melakukan program pembangunan yang bergerak dibidang pembangunan fisik saja tetapi juga harus bergerak dibidang pembagunan non fisik atatu sosial.Pembangunan nonn
p-ISSN 2302-6960

e-ISSN 2716-165X

fisik disini berartu sebuah pembangunan yang digunakan untuk memenuhi kehidupan sosial masyarakat". Bachtiar Effendi (2002:114) "oleh karena itu, pembangunan hendaknya harus adanya keseimbangan antara pembangunan fisik ataupun pembangunan non fisiknya, bagian dari pembangunan non fisik atau sosial yaitu:

1) Pembangunan manusia yaitu suatu proses yang ditujukan untuk masyarakatmemperluas pilihan-pilihan bagipenduduknya sebagai tujuan akhir dan upaya pembangunan itu sendiri dan sebagai saran utama dalam rangka mencapai tujuan itu. Pembangunan manusia disini yakni suatu proses pembangunan yang dilakukan untuk meningkatkan kemampuan masyarakat itu sendiri. Seperti PKK dan Program pelatihan pembuatan kue.

2) Ekonomi Pembangunan ekonomi merupakan upaya yang dilakukan oleh suatu negara dengan tujuan mengembangkan kegiatan ekonomi. Pembangunan ekonomi ini berarti suatu usaha yang dilakukan pemerintah dalam meningkatkan perekonomian masyarakatnya.

3) Kesehatan. Pembangunan kesehatan adalah pembangunan nasional yag bertujuan meningkatkan kesadaran, kemauan, dana kemampuan hidup sehat bagi setiap orang agar terwujud kesehatan masyarakat yabg setinggi tigginya. Kesehatan disini adalah suatu proses pembangunan yang digunakan umtuk meningkatkan kesaadaran masyarakat dalam hal kemampuan kesehatannya yakni dalam hal ini meningkatkan kemampuan budaya hidup sehat. Seperti pemeriksahan kesehatan secara rutin (posyandu).

4) Pendidikan yang dutujukan kepada orang dewasa, termasuk wanita di luar batas umur tertinggi kewajiban belajar, dan dilakukan di luar lingkungan dan sistem pengajaran. Pendidikan disini merupakan proses pembangunan yang ditujukan pada kemampuan peningkatan pendidikan yang dimiliki setiap masyarakat khususnya pada wanita. Pendidikan non formal seperti pelatihan menjahit dan pembuatan kue". 


\section{Faktor-faktor yang mempengaruhi partisipasi}

a. Faktor Intern Faktor Kesadaran / Kemauan":

1) Keikutsertaan didalam suatu kegiatan pembangunan bukannya timbul begitu saja akan tetapi karena adanya yang mendorongnya untuk partisipasi. Salah satu diantaranya adalah faktor kesadaran masyarakat itu sendiri..

2) Faktor Pendidikan Salah satu faktor yang menyebabkan terjadinya berbagai perubahan di muka bumi ini adalah karena faktor pendidikan.

3) Faktor Penghasilan / Pendapatan Setelah mengetahui bahwa faktor pendidikan amat berpengaruh pada partisipasi masyarakat pada pembangunan, maka berikut iniakan dijelaskan juga bagaimana pengaruh penghasilan I pendapatan pada pembangunan, khususnya pada bentuk sumbangan uang / dana".

b. Faktor Ekstern

1) "Kepemimpinan Pemerintah Karena masyarakat adalah paduan dari beberapa individu yang memiliki kemampuani yang berbeda, maka untuk memadukannya diperlukan kekuatan yaitu kemampuan suatu pendinamisan oleh pimpinan pemerintah, dalam hal ini yaitu pemerintah desa:".

2) "Peralatan / FasilitasDalam pelaksanaan tugas kepala Desa/Kelurahan dan perangkatnya, dibutuhkan kantor Desa/Kelurahan yang merupakan tempat untuk melaksanakan tugas pengelolaan, pelaporan, pencatatan dan berbagai kegiatan lainnya".

\section{B. METODE PENELITIAN}

Penelitian ini, peneliti menggunakan dua variabel yakni partisipasi wanita sebagai variabel independen (bebas)dan pembangunan non fisik sebagai variabel dependen (terikat). Penelitian ini menggunakan tipe penelitian deskriptif kuantitatif, untuk memberikan gambaran e-ISSN 2716-165X dengan cermat, jelas dan objektif maka diharapkan metode ini dapat memberikan penjelasan secaracermat, jelas dan objektif terhadap masalah yang akan diteliti.

Populasi adalah kumpulan dari keseluruhan pengukuran, objek, atau individu yang sedang dikaji (Jamaluddin, 2015:137). Populasi dalam penelitian ini sebanyak 411 wanita di Kelurahan Kadidi sedangkan Sampel adalah sebagian atau subset (himpunan bagian), dari suatu populasi (Jamaluddin, 2015:140).Pada penelitian ini menggunakan sampel yaitu sampling insidental.Sampel pada penelitian ini yaitu 80 wanita.

Teknik pengumpulan data, yang meliputi Observasi Penelitian pustaka, dan Kuesioner/Angket. Berdasarkan jenis data yang sudah terkumpul, maka dilakukan analisis dengan bantuan tabel frekuensi dan SPSS 20. Nilai- nilai varian sebagai hasil olahan data akan menggambarkan suatu hubungan antara variabel yang satu dengan variabel lainnya. Data hasil penelitian dianalisis dengan alat statistik yang terdiri dari: Analisis Deskriptif, Uji Kualitas Data (Validitas dan reabilitas), Uji Asumsi Klasik, Regresi Linear sederhana dan Pengujian Hipotesis.

\section{HASIL DAN PEMBAHASAN}

Hasil penelitian Partisipasi Wanita(X) a) partispasi dalam pengambilan keputusan sebesar 58,6\%, b). Partispasi dalam pelaksanaan kegiatan sebesar $60,2 \%$, c). Partispasi dalam pemantauan dan evaluasi sebesar 52,2\%, d) Partisipasi dalam pemanfaatan hasil pembangunan sebesar $56,5 \%$. Dari keempat indicator diperoleh hasil $56,87 \%$ atau berada pada kategori kurang baik

Hasil penelitian Pengelolaan Dana Desa ( $Y$ ) yaitu diperoleh hasil a). Pembangunan Manusia sebesar 60,6\%, b). Ekonomi sebesar $61,4 \%$, c) Kesehatan sebesar 55,6\%, d). Pendidikan sebesar $62,4 \%$. Dari keempat indikator di peroleh hasil $60 \%$ Maka, disimpulkan bahwa pembangunan non fisik di Kelurahan Kadidi berada ada kategori kurang baik.

Hasil penelitian Faktor-faktor yang mempengaruhi partisipasi wanita $(F)$ yaitu diperoleh hasil Faktor Intern: (a). Keikutsertaan sebesar 59,2\% (b). Pendidikan sebesar $62,2 \%$ (c). Penghasilan/Pendepatan sebesar 64,6\% Faktor Ekstern: (a). 
Kepemimpinana sebesar 65,2\% (b).

Peralatan Fasilitas Pemerintah sebesar $60,6 \%$. Dari kelima indikator tersebut diperoleh $62,36 \%$ dapat disimpulkan bahwa faktor yang mempengaruhi partisipasi berada pada kategori baik

\section{Uji Validitas}

Berdasarkan hasil olah data diketahui bahwa 4 item pertanyaan yang digunakan untuk mengukur variabel Partisipasi Wanita (X) dinyatakan valid dengan nilai corrected item-total correlation $>0.25,0.30$ (corrected item-total correlation $>0.25,0.30$ ) yaitu X1:0.664, X2:0.474,X3:0.596, X4:0.641, hasil dari item total statistic diatas, diketahui bahwa 4 item pertanyaan yang digunakan untuk mengukur variabel (pembangunan non fisik) dinyatakan valid dengan nilai corrected item-total correlation lebih besar dari $>0.25$, 0.30 (corrected item- total correlation $>0.25$, 0.30). yaitu Y1:0.404, Y2:0.409, Y3:0.435, Y4:0.407. hasil dari item total statistic diatas, diketahui bahwa 5 item pertanyaan yang digunakan untuk mengukur variabel (pembangunan non fisik) dinyatakan valid dengan nilai corrected item-total correlation lebih besar dari $>0.25,0.30$ (corrected itemtotal correlation> $0.25,0.30$ ). yaitu $\mathrm{F} 1: 0.577$, F2:0.257, F3:0.340, F4:0.272, F5: 0,593.

\section{Uji Reliabilitas}

Berdasarkan reliability statistics, kuesioner penelitian yang digunakan untuk mengukur variabel $X$ reliabel atau hAparaturl karena Cronbach Alpha yang diperoleh adalah sebesar 0.784 yang berarti lebih besar dari $0.60(0.784>0.60)$. Berdasarkan UJI reliability statistic, kuesioner penelitian yang digunakan untuk mengukur variabel $Y$ reliabel karena Cronbach Alpha yang diperoleh adalah sebesar 0.634 yang berarti lebih besar dari $0.60(0.634>0.60)$, reliability statistic, kuesioner penelitian yang digunakan untuk mengukur variabel $F$ reliabel atau hAparaturl karena Cronbach Alpha yang diperoleh adalah sebesar 0.649 yang berarti ebih besar dari 0.60 $(0.649>0.60)$

\section{Uji Asumsi Klasik}

Berdasarkan dari uji grafik normal P-P Plot hasil olah data, maka model regres dalam penelitian ini memenuhi asumsi normalitas yakni data menyebar di sekitar garis diagonal dan mengikuti arah garis diagonal, atau grafik histogramnya menunjukkan pola distribusi normal, maka resgresi memenuhi asumsi normalitas.

\section{Regresi Linear dan Hipotesis}

Bagian output model summary, pada bagian ini ditampilkan nilai $R$ pada tabel di atas didapatkan 0,588, artinya kolerasi antara variabel partisipasi wanita terhadap pengelolaan dana desa sebesar 0.588 , hal ini berarti terjadi hubugan yang erat karena nilai tersebut mendekati 1. Nilai R2 sebesar 0.545 artinya persentase sumbangan pengaruh variabel pembangunan non fisik terhadap faktor yang mempengaruhi partisipasi wanita sebesar 54,5\%. Sedangkan sisanya dipengaruhi sebesar $45,5 \%$ dipengaruhi oleh variabel lain yang tidak dimasukkan ke dalam model ini. Adjusted Rsquare adalah $\mathrm{R}$ square yang telah disesuaikan, nilai $R$ square sebesar 0,455 menunjukkan sumbangan pengaruh variabel independen terhadap variabel dependen.Kesalahan prediksi nilai sebesar 2.11582 .

Hasil dari uji ANOVA pada bagian ini ditampilkan hasil yang diperoleh adalah nilai $\mathrm{F}$ $=41.148$ dengan tingkat probabilitas sig. 0.000 . Oleh karena probabilitas $(0,000)$ jauh lebih kecil dari 0.05, maka model regresi bisa dipakai untuk memprediksi Partipasi Wanita. Untuk menguji kebenaran hipotesis dalam penelitian ini dilakukan uji F. Untuk mengetahui bahwa pengaruh/Signifikan dapat diketahui dengan melihat dari lefel of signifikan $a=0,05$. Jika nilai signifikan lebih kecil dari 0,05, maka $\mathrm{HO}$ ditolak dan Ha diterima.

Berdasarkan hasil olah pada tabel ANOVA, maka diketahui nilai Fhitung yang diperoleh sebesar 41.148 dengan tingkat signifikan 0,000 (Sig < 0,05) yang berarti bahwa variabel Partisipasi Wanita (X) mempunyai pengaruh/signifikan terhadap Pembangunan Non Fisik (Y), dari hasil tersebut berarti model regresi dapat digunakan untuk memprediksi keterkaitan antara Partisipasi Wanita dalam Pembangunan Non Fisik di Kelurahan Kadidi Kecamatan Pancarijang Kabupaten Sidenreng Rappang.

Berdasarkan tabel Coefficients hasil olah data, maka model regresi yang digunakan dalam penelitian ini untuk mengukur pengaruh Partisipasi Wanita dalam Pembangunan Non Fisik di Kelurahan Kadidi Kecamatan Panca Rijang Kabupaten Sidenreng Rappang.

$$
Y=3.336+1.339 X
$$

Dari fungsi regresi di atas, maka dapat dijelaskan :

1. Jika variabel Partisipasi Wanita (X) berubah, maka Pembangunan Non Fisik 
(Y) juga akan berubah. Tanda positif menunjukkan perubahan yang searah. Apabila Partipasi Wanita meningkat, maka Pembangugan Non Fisik juga akan meningkat dengan koefisien regresi sebesar 1.339 dan sebaliknya, jika Partisipasi Wanita menurun, maka Pembangunan Non Fisik juga akan menurun dengan koefisien regresi sebesar 1.339 .

2. Nilai konstanta sebesar 3.336 menunjukkan bahwa, jika semua variabel konstan maka Partisipasi Wanita masih bersifat positif.

Uji statistic $t$ untuk menunjukkan seberapa jauh pengaruh satu variabel penjelas/independen secara individual menerangkan variasi variabel dependen berdasarkan tabel coefficients hasil olah data SPSS, maka diketahui bahwa :

a. Nilai $t$ hitung variabel Partisipasi Wanita (X) 6.415 dengan tingkat signifikan 0,000.

b. Hipotesis berdasarkan uji $\mathrm{t}$ dirumuskan secara statistic

$$
\begin{aligned}
& \mathrm{Ha}: \text { Pyx } \neq 0 \\
& \mathrm{HO}: \text { Pyx } \neq 0
\end{aligned}
$$

Hipotesis bentuk kalimat:

1. $\mathrm{Ha}$ : Partisipasi Wanita berpengaruh/signifikan dalam Pembangunan Non Fisik di Kelurahan Kadidi Kecamatan Panca Rijang Kabupaten Sidenreng Rappang.

2. HO : Partisipasi Wanita tidak berpengaruh/signifikan dalam Pembangunan Non Fisik di Kelurahan Kadidi Kecamatan Panca Rijang Kabupaten Sidenreng Rappang

Pengambilan Keputusan :

1. Jika nilai $t$ hitung $\geq t$ tabel, maka $\mathrm{HO}$ ditolak dan Ha diterima, artinya Signifikan

2. Jika nilai $t$ hitung $\leq t$ tabel, maka $\mathrm{HO}$ diterima dan $\mathrm{Ha}$ ditolak, artinya tidak Signifikan

Tabel Coefficients diperoleh $\mathrm{t}$ hitung $=$ 6.415 prosedur mencari statistic tabel dengan kriteria

1. Tingkat signifikan $(a=0,05)$

2. $\mathrm{df}=$ Jumlah Responden -2 atau $80-2=$ 78

3. $\mathrm{t}$ tabel $=\mathrm{a} / 2 ; \mathrm{df}$

$$
=0,05 / 2 ; \mathrm{df}
$$

$$
=0,025 ; 78
$$

Sehingga $t$ tabel $=0,219$

Keputusan :

Ternyata nilai $\mathrm{t}$ hitung $>\mathrm{t}$ tabel atau $6.415>0,219$, maka $\mathrm{HO}$ ditolak dan $\mathrm{Ha}$
p-ISSN 2302-6960

e-ISSN 2716-165X

diterima, artinya signifikan.Jadi, Partisipasi Wanita berpengaruh signifikan dalam Pembangunan Non Fisik di Kelurahan Kadidi Kecamatan Panca Rijang Kabupaten Sidenreng Rappang.

Berdasarkan pada keputusan yabg telah dipaparkan tentang pengujian hipotesis dapat dijelaskan bahwa Ho ditolak dan Ha diterima dengan kata lain $\mathrm{t}$ hitung $>\mathrm{t}$ tabel (6.415 > $0,219)$. Begitu pula dengan nilai signifikannya dari output diperoleh sebesar 0,000 dengan kata lain nilai sigifikannya lebih < dari 0,05. Dari data tersebut dapat dikatakan bahwa Partisipasi Wanita berpegaruh signifikan terhadap Pembangunan Non Fisik di Keluahan Kadidi Kecamatan Panca Rijang Kabupaten Sidereng Rappang. Pembagunan disuatu wilayah tidkak hayna melaksanakan program pembagunan yang bergerak dibidang pembangunan non fisik atau sosial.Bachtiar Effendi (2002:114)oleh sebab itu pembagunan kiranya harus adanya keseimbangan antara pembangunan fisik ataupun pembangunan non fisiknya.

Pembangunan non fisik berkenaan pada pembangunan sumber daya manusia itu sendiri.Adapun pembagunan non fisik meliputi pembangunan di bidang kesehatan, pembangunan di bidang pendidikan, pembangunan di bidang ekonmi dan lain sebagainya.Pembangunan non fisik mengedepankan sumber daya manusia, disebabkan karena adanya pembangunan nonfisik menjadi dasar untuk melakukan pembangunan fisik. Keberhasilan suatu proses pembagunan tidak bisa dilepaskan dari adanya partisipasi anggota masyarakatnya, baik sebagai kesatuan sistem ataupun sebagai individu yang bagian yang sangat integral yang amat penting pada proses dinamika pembangunan ditunjukkan guna mewujudkan masyarakat yang sejahtera. Oleh karenanya itu tanggungjawab berhasil tidaknya pembagunan tidak saja ditangan pemerintah tetapii juga ditangan masyrakat.

Kesadaran serta partisiipsasi aktif dari masyarakaadalah salah satu kunci keberhasilan pembagunan,dalam hal ini mencapai target pembagunan perlu ditunjukkan oleh kebijaksanaan pemerintah.Sehubungan degan itu didapat diikatakan bahwa pembangunan yabg sedang dalam proses ditentukan oleh besar kecilnya partisipasi masyarakat adalah Partisipasi dlam perencanaan, Partisipasi dalm Pelaksanaan, Partisipasi dalam pengawasan dan penilaian. 
Pada dasarnya, tujuan tahap ini adalah membangun kepercayaan satu sama lainnya (mutual trust) dan kemitraan yang akan menjadi dasar pijakan relasi antara individu/kelompok masyarakat dan pihak yang berkepentingan dan pemberdayaan masyarakat tersebut. Dalam tahap ini, setiap anggota masyarakat dalam hal ini wanita yang tergabung dalam berbagai kelompok atau organisasi yang ada di tingkat RT, RW, maupun desa/kota diharapkan turut serta dalam proses membangun komitmen ini. Proses yang dilakukan dalam rangka membangun komitmen ini dilakukan melalui komunikasi yang menitik beratkan pada musyawarah atau kesepakatan. Komunikasi yang dilakukan dalam tahapan ini adalah FGD (Focus Group Discussion) yang melibatkan partisipan-partisipan untuk melakukan pertukaran pesan sebagai upaya membangun komitmen bersama dalam pembangunan partisipatif.

Data distribusi frekuensi variabel partisipasi wanita dapat dilihat bahwa tingkat capaian responden sebesar $56,87 \%$. Ini memperlihatkan bahwa nilai tingkat capaian responden berada pada kategori kurang baik maka dari itu partisipasi wanita diharapkan lebih oprimal dalam pembangunan non fisik, menyangkut keiikutsertaan dalam pengambilan keputusan, pemantauan dana evaluasi kinerja, serta pemanfaatan hasil dalam pembangunan non fisik. Hasil analisis data pembangunan non fisik di Kelurahan Kadidi bahwa tingkat pencapaian responden sebesar $60 \%$ berada pada kategori kurang baik, dimana dalam pembangunan non fisik yang ada dilokasi penelitian masih dinilai kurang dalam memilih jenis kegiatan sesuai dengan yang dibutuhan oleh wanita serta kurangnya upaya yang dilakukan pemerintah dalam menangani masalah kesehatan yang ada dimasyarakat. Berdasarkan hasil analisis data faktor-faktor yang memengaruhi partisipasi wanita di Kelurahan Kadidi bahwa tingkat pencapaian responden sebesar 62,36 $\%$ berada pada kategori baik , seperti ikutserta dalam memberikan sumbangan uang/dana dari kelompok wanita serta kemampuan pemerintah dalam mengarahkan wanita untuk berpartisipasi meskipun keikutsertaan wanita dalam proses pembangunan non fisik dinilai masih perlu ditingkatkan.

$\begin{array}{lll}\text { Hasil } & \text { penelitian bahwa } & \text { keikutsertaan } \\ \text { wanita } & \text { mempengaruhi } & \text { keberhasilan }\end{array}$
p-ISSN 2302-6960

e-ISSN 2716-165X

pembangunan non fisik yang ada di Kelurahan Kadidi Kecamatan Panca Rijang Kabupaten Sidenreng Rappang, apabila keikutsertaan wanita dalam kegiatan tersebut meningkat maka keberhasilan kelompok wanita dalam mencapai tujuan pembangunan non fisik yang sesuai dengan kebutuhan wanita yang ada dilokasi penelitian dapat optimal. Hal ini sejalan dengan penelitian yang telah dilakukan oleh Rini Rinawati 2004 yang dilakukan tentang partisipasi wanita dalam pembangunan di jawa barat menunjukkan bahwa terdapat pengaruh partisipasi wanita dalam pembangunan.Wanita sebagai bagian dari masyarakat melalui berbagai kelompok atau organisasi yang ada di lingungannya memiliki peranan yang sangat penting dalam paradigma pembangunan partisipatif, khusunya melalui pendekatan pemberdayaan masyarakat.

Berdasarkan hal tersebut maka wanita dikatakan berpartisipasi apabila dalam segala kegiatan dalam pembangunan non fisik, wanita mampu berperan aktif dalam setiap proses kegiatan perencanaan, pelaksanaan, monitoring, dan evaluasi pembangunan tersebut seperti memberikan peluang dan kemudahan kepada wanita untuk ikut merancang program atau kegiatan yang sesuai dengan kebutuhan serta mampu meningkatkan Pembangunan manusia, ekonomi, kesehatan dan pendidikan yang ada di Kelurahan Kadidi.

\section{KESIMPULAN}

Berdasarkan dengan hasil dan pembahasan yang ada diatas maka hal ini dapat disimpulkan sebagai berikut:

1. Berdasarkan hasil perhitungan SPSS versi 21 maka, t hitung $>\mathrm{t}$ tabel atau 6,415 > 0,219 , maka HO ditolak dan Ha diterima, artinya signifikan. Jadi Partisipasi Wanita berpengaruh signiifikan terhadap Pembangunan Non Fisik di Kleurahan Kadidi Kecamatan Panca Rijang Kabupaten Sidenreng Rappang dengan persentase sumbangan sebesar $54,5 \%$.

2. Hasil penelitian Faktor-fakktor yang Mempengaruhi Partisipasi Wanita: a. Faktor Internal: 1) Keiikutsertaan 59,2\%, 2) Pendidikan $62,2 \%, 3)$ Penghaslan dan pendapatan $64,6 \%$. b. Faktor Eksternal: 1) Kepemimpinan 65,2\%, 2) Peralatan/ Fasilitas Pemerintah 60,6\%. Berdasarkan dari uraian tersebut di atas, maka dapat disimpulkan bahwa faktor-faktor yang 
mempengaruhi partisipasi wanita di

Kleurahan Kadidi berada pada kategori baik $62,36 \%$ seperti ikutserta dalam memberikan sumbangan uang/dana dari kelompok wanita serta kemampuan pemerintah dalam mengarahkan wanita untuk berpartiisipasi meskipun keikutsertaan wanita dalam proses pembangunan non fisik dinilai masih perlu ditingkatkan.

\section{E. DAFTARPUSTAKA}

Ahmad, jamaluddin.2015. Metode Penelitian Administrasi Publik Teori dan Aplikasinya, Gave Media, Yogjakarta.

Ardieansyah, Welasari 2014 Analisis Partisipasi Masyarakat Dalam Pembangunandi Desa Makeruhkecamatan Rupat Kabupaten Bengkalis.

Effendi, bachtiar 2002. Pembangunan Daerah Otonom Berkeadilan. Yogyakarta: pt uhindo dan offset.

Remiswal. 2013. Menggugah Partisipasi Gender di Lingkungan Komunitas Lokal. Graha IImu. Yogyakarta.

Sugiono. 2017. Metode Penelitian Administrasi. Alfabeta.Badung.

Zainuddin. 2017. Teori-Teori Mutakhir Dalam Perspektif IImu Administrasi Publik. Makassar : Phinatama Media (Phinisi Utama Media).

\section{DOKUMEN}

UU Nomor 6 Tahun 2014 tentang Pembangunan Desa. 